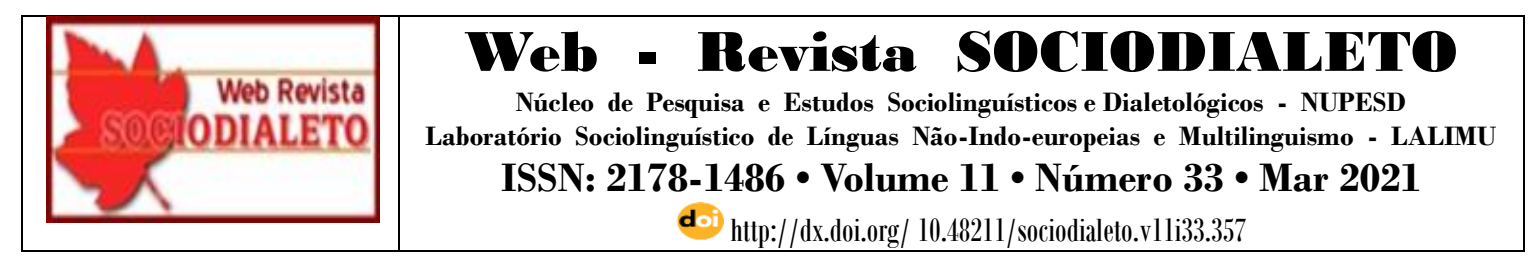

\title{
LÍNGUAS EM CONTATO: AS PRÁTICAS SOCIAIS E DISCURSIVAS DA TRÍPLICE FRONTEIRA BRASIL, COLÔMBIA E PERU
}

\section{LANGUAGES IN CONTACT: THE SOCIAL AND DISCURSIVE PRACTICES OF THE TRIPLE BORDER BRAZIL, COLOMBIA AND PERU}

\author{
Dayane Lima Viana (PPGLin-UFSC) ${ }^{1}$ \\ dayanelimaviana@,gmail.com
}

\author{
Felício Wessling Margotti (UFSC) ${ }^{2}$ \\ felício.margotti@ufsc.br
}

\begin{abstract}
RESUMO: Através desta pesquisa, pretendemos discutir os efeitos do contato de línguas na tríplice fronteira Brasil, Colômbia e Peru. Nosso estudo foi pautado na Sociolinguística Variacionista de Weinreich, Labov e Herzog (1968). Essa corrente advoga que a análise linguística deve ter como princípio a consideração de que a língua e a sociedade estão intimamente ligadas. É nessa perspectiva que a intrínseca relação linguagem e sociedade aqui é evocada. Nosso principal objetivo foi descrever as práticas sociais e discursivas particulares à tríplice fronteira. Também traçamos um panorama social a fim de revelar como os aspectos sociais condicionam a variação linguística na cidade de Tabatinga-AM. A importância desse trabalho está no caráter inédito do estudo, uma vez que não há pesquisas publicadas sobre esse tema nessa tríplice fronteira.
\end{abstract}

PALAVRAS-CHAVE: Contato. Práticas sociais. Variação.

\begin{abstract}
Through this research, we intend to discuss the effects of language contact on the triple frontier among Brazil, Colombia and Peru. Our study was based on the Variationist Sociolinguistics of Weinreich, Labov and Herzog (1968). This current advocates that linguistic analysis should take as a principle the consideration that language and society are closely linked. In this perspective that the intrinsic relationship between language and society is evoked here. Our main objective was to describe social and discursive practices particularly at the triple frontier, we also draw a social panorama in order to reveal how social aspects condition linguistic variation in Tabatinga, a city in Amazonas. The importance of this work is the unprecedented nature of the study, since there is no published researches on this topic in this triple frontier.
\end{abstract}

\footnotetext{
${ }^{1}$ Graduação em Letras Língua Portuguesa pela Universidade do Estado do Amazonas. Mestre em Letras na Área de Concentração Estudos da Linguagem pelo Programa de Pós-Graduação em Letras- PPGL da UFAM. Doutoranda do Programa de Pós-graduação em Linguística da Universidade Federal de Santa Catarina - UFSC. Área de Concentração: Teoria da Variação e Mudança linguística. Linha de Pesquisa: Contato linguístico.

2 Professor Titular da Universidade Federal de Santa Catarina. Licenciado em Letras (1975), cursou mestrado em Linguística na UFSC (1982) e doutorado em Letras na UFRGS (2004). Atua no ensino de Língua Portuguesa, Dialetologia e Sociolinguística. Dedica-se aos estudos geossociolinguísticos, com participação na elaboração do Atlas Linguístico-Etnográfico da Região Sul do Brasil - ALERS e no Projeto Atlas Linguístico do Brasil - ALiB. Atualmente, é professor Voluntário do Programa de Pós-Graduação em Linguística da Universidade da UFSC.
} 


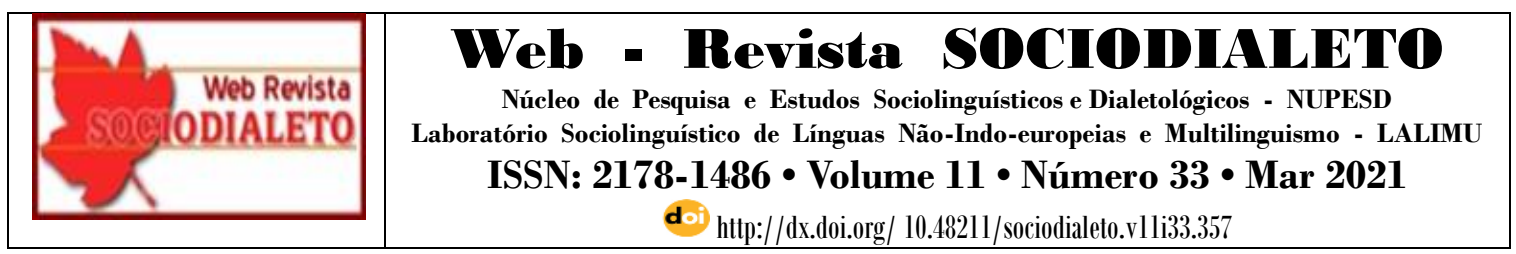

KEYWORDS: Contact; Social practices; Variation.

\section{Introdução}

Tabatinga é a última cidade do extremo Oeste do Amazonas e, por ser interligada com a cidade de Letícia (Colômbia) e Santa Rosa (Peru), apresenta-se com um inegável contexto multifacetado. Neste espaço, línguas e culturas distintas são indiscutivelmente um imperativo natural, e os estreitos laços sociais e culturais determinam uma conjuntura social marcadamente pluriétnica. Como é de conhecimento geral, as consequências do contato entre as línguas são muitas. Esse entendimento abre espaço para as diversas perspectivas de estudo.

Este contato está configurando a fala tabatinguense por meio de influências externas que integram o "conjunto complexo de correlações sociais" (MOLLICA, 2015), pois, além da cotidiana interação entre brasileiros, colombianos e peruanos através das relações comerciais e culturais, os casamentos interétnicos, as políticas educacionais, as atividades laborais e as festividades também imprimem marcas no vernáculo destes falantes. Isso reforça o trans culturalismo que, de acordo com Peixoto (2009), são pontos de contato entre diferentes culturas que formam contornos distintos na dinâmica social de dada sociedade.

Muitas pesquisas dedicam-se ao estudo dos impactos que resultam do contato, e a concepção de influência é bem difundida, pois esses cenários singulares e idiossincráticos podem conduzir o falante a desenvolver a competência linguística em ambas as línguas ou criar pressões para absorção de determinados traços do dialeto em contato.

\section{Línguas em Contato e Sociedade: algumas implicações teóricas}

As fronteiras físicas não são necessariamente fronteiras linguísticas, pois o contato entre as línguas é uma consequência inevitável. Com suas marcas, o contato linguístico imprime novas configurações que são permeadas por meio das redes comunicativas, 


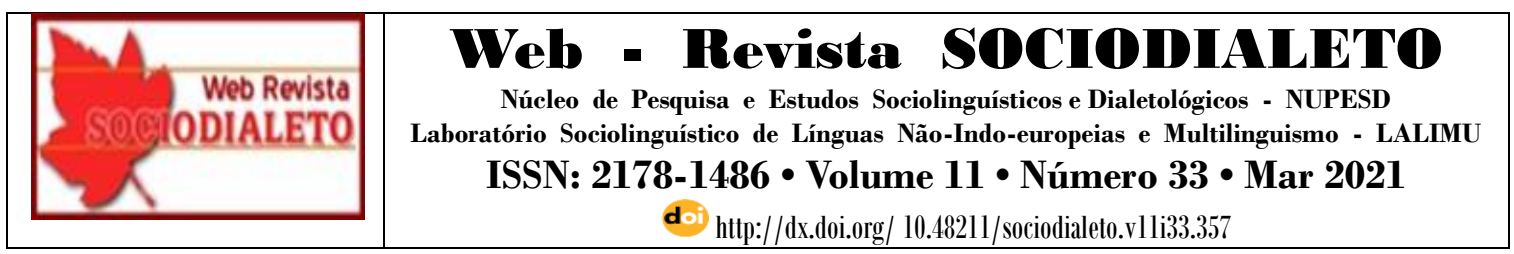

favorecendo assim o desenvolvimento de um cenário indiscutivelmente heterogêneo e diversificado (MOLLICA, 2004).

Para Benveniste (1976, p. 27), “a linguagem sempre se realiza dentro de uma língua, de uma estrutura linguística definida e particular, inseparável de uma sociedade definida e particular. Logo, língua e sociedade não podem ser concebidas uma sem a outra". É nesse sentido que Alkmim (2012, p.23) enuncia que: "linguagem e sociedade estão ligadas entre si de modo inquestionável", fundamento segundo o qual todo aquele que se debruça sobre o estudo das línguas deve primariamente considerar tal pressuposto.

Desse modo, quando as línguas em contato passam a conviver no mesmo contexto social, as relações comunicativas são desencadeadas por diversos fatores externos à língua, podendo ser de caráter social, comercial e cultural.

É nesta perspectiva sociológica que os termos linguagem e sociedade são intrinsecamente evocados por Benveniste (1963), pois “[...] é dentro da e pela língua que indivíduos e sociedade se determinam mutuamente". A determinação mútua proposta por Benveniste recai também sobre os fenômenos de contato, uma vez que a realidade entre as fronteiras linguísticas não são limitadas. O que ocorre ali são extensas aberturas às configurações sociais que, por consequência, desencadeiam a variação das línguas envolvidas.

Ao citar Fasold (1996), Padovani e Sanches (2016) esclarecem que, quando se trata da variação dentro do corpo social, é necessário considerarmos os múltiplos aspectos que a determinam, uma vez que as variantes não estão "exclusivamente" associadas a um grupo ou outro. Isto ocorre quando falantes de diferentes comunidades interagem. Nesse contexto, ambos os grupos podem usar as variantes que lhes são próprias, e no mesmo instante utilizar as variantes do grupo com o qual estão em contato.

É justamente o contato com distintas comunidades que "favorece a entrada de novas formas linguísticas", e permite que de modo natural as línguas sejam recriadas a partir de ações individuais que imprimem modificação ao coletivo:

Isto se dá porque, por meio da língua, o homem recria a realidade, interpretando-a e repassando-a aos demais. Aprisionado às suas 


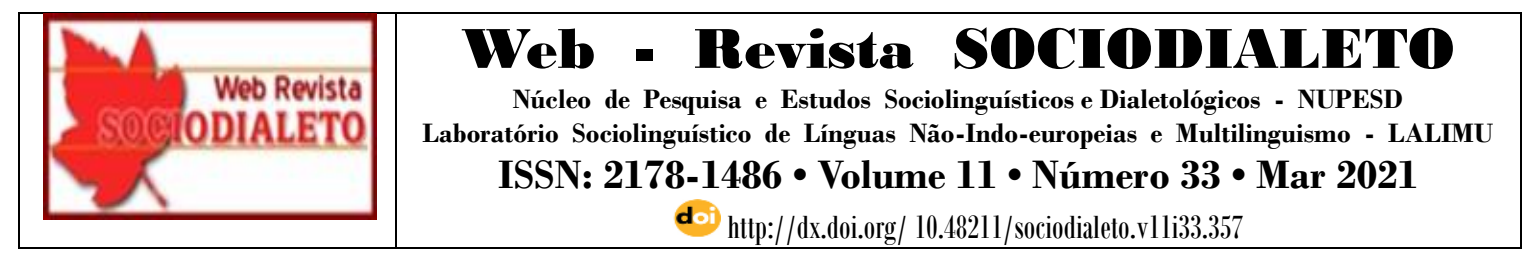

estruturas, obediente às regras que lhe garantem a intercomunicação, preserva formas tradicionais; sensível às modificações que se operam a sua volta, nela imprime suas marcas, renovando-a a cada apelo externo. (BRANDÃO, 2013, p. 359)

Com isso, podemos aqui afirmar que a realidade vivenciada pelo falante de zona de fronteira, pode determinar no surgimento de fenômenos em variação. Ao conceber esse fato, consideramos o próprio falante como agente modificador de sua língua, é a respeito disso que Espiga (2006, p. 263) enuncia: "há comunidades e passos de fronteira que conhecem e partilham, a ambos os lados da linha, a mesma geografia, história e cultura local, descritas e vivenciadas em português e espanhol ou em dialeto próprio, misto das duas línguas".

A consideração dos fatos sociais como fator determinante na língua é também defendido por Ogliari (2006, p.303) quando esclarece que "os estudos sobre situações vivenciadas entre línguas coexistentes consideram como postulado básico a afirmação de que a história das línguas, ou mesmo da língua, associa-se intimamente à história social do povo que a fala".

Alkmim (2012, p. 41) também enfatiza que as variedades linguísticas não ocorrem no vácuo, mas no contexto das relações sociais estabelecidas pelas estruturas sociopolíticas de cada comunidade de forma "lenta e gradual".

Coan (2006) advoga que as línguas não são transformadas de modo direto e abrupto, substituindo um elemento pelo outro rapidamente, pois tudo se inicia com uma envolvente concorrência, o que leva o falante a operar com "regras variáveis" dentro de um "padrão sistemático [...]". É justamente o contato com outras línguas que faz surgir a variação e as mudanças na estrutura nas línguas faladas pelos que vivem em região de fronteira.

\section{Condicionadores linguísticos e não linguísticos}




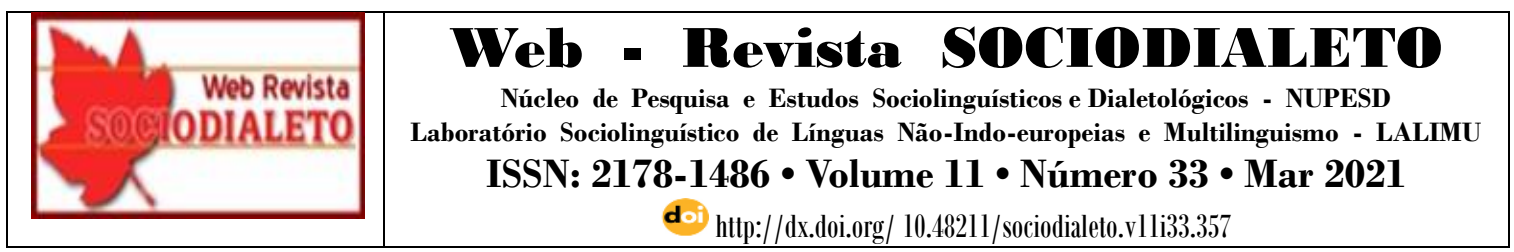

As investigações sociolinguísticas passam a conceber a língua como um sistema inerentemente heterogêneo, aberto às alterações e mudanças, seja por fatores internos ao próprio sistema ou externos a ele.

Aqui chegamos ao enfoque dos influenciadores internos e externos que Coelho et al. (2015, p. 19) denomina-os como condicionadores, ou seja, para eles "existem forças dentro e fora da língua que fazem um grupo de pessoas ou um único indivíduo falar da maneira como fala".

Segundo a perspectiva sociolinguística, a atuação dos condicionadores, que também são chamados de variáveis dependentes $e$ independentes, orientam $\mathrm{e}$ condicionam as escolhas linguísticas do falante.

As variáveis dependentes são aquelas de natureza fonológica, morfológica, sintática, semântica etc. E são, portanto, reflexos dos fenômenos linguísticos observáveis dentro de uma comunidade.

Labov (1972) assumiu a importância dessa perspectiva de estudo, entretanto, de acordo com a sua concepção, não se pode restringir a variação e a mudança a fatores “estritamente linguísticos", pois, para se chegar as explicações dos fatos, é necessário entender de modo aprofundado como e quais forças operam nas línguas (CHAGAS, 2015).

As variáveis independentes, por sua vez, são as que mantêm vínculo direto com o social. É o conjunto de fatores extralinguísticos que impõe variação a depender da faixa etária dos falantes, do gênero, da classe social, do grau de escolaridade, entre outros.

Ao considerar a importância dos condicionadores para os estudos linguísticos, entende-se que o campo de discussão se torna mais frutífero quando analisamos as variáveis linguísticas e sociais.

Nesse escopo de discussão, torna-se imprescindível observar que "as variáveis não agem isoladamente, mas operam por um conjunto complexo de correlações que inibem ou favorecem o emprego de formas variantes semanticamente equivalentes" (MOLLICA,2015, p. 27). 


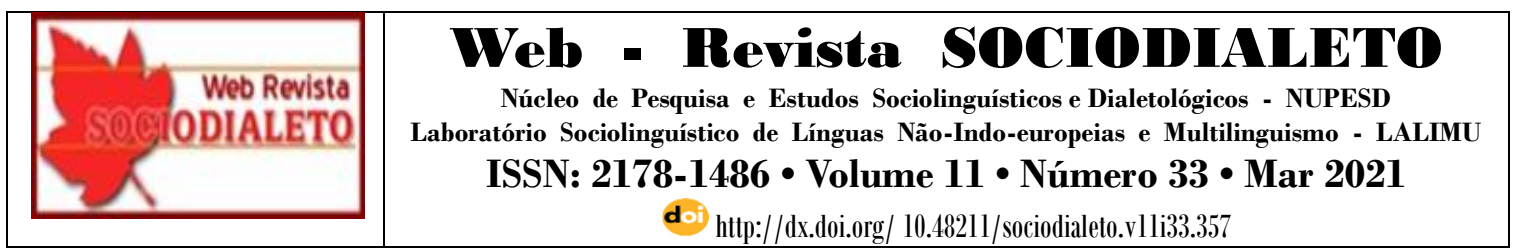

Portanto, ao considerar o "uso da língua dentro do contexto social", assumimos que fatos variados podem incidir alterações na fala do indivíduo ou da sociedade como um todo, pois os reflexos das "forças externas interagem com forças internas", demonstrado in vivo os jogos ativos da variação (DIAS,1996, p. 126); (REIS, 2011).

\section{Fronteira: um espaço de mudanças}

Todo espaço de fronteira deve ser considerado como um portal que tem o poder de mudar as pessoas e seu ambiente original. Na medida que esse espaço difuso e heterogêneo ganha expansão através das redes de comunicação diversas, a fronteira se transforma em uma zona de transição. Nesse sentido, uma fronteira pode ter um poder quase mágico, uma fronteira pode liberar ou aprisionar, antagonizar ou integrar. (GARCIA, 2010)

Ao descrever sobre os aspectos gerais de Tabatinga e Letícia, Suarez (2013) atribui à fronteira brasileira um cenário pluriétnico e multicultural, que confere à cidade "um mundo cosmopolita e dinâmico" que, de modo interativo, é implementado pelo fluxo humano e pelos traços culturais peculiares e idiossincráticos.

De igual modo, Suarez (op. cit) considera que cidades de fronteira mantêm entre si "uma fluida relação", que implica diretamente em diferentes manifestações sociais e culturais. Ele ressalta que as relações independem das linhas divisórias, e que é a partir das situações variadas que formam a identidade sociocultural dos que ali estão imergidos.

É a respeito dessas manifestações multiculturais que se entrecruzam em Tabatinga, que o autor tece o seguinte comentário:

defronta-se ao mesmo tempo com duas culturas e duas nacionalidades diferentes, porém complementaria: a colombiana e a peruana". E juntas formam novas visões de mundo dentro do espaço brasileiro, que por suas marcas e especificidades tornam os indivíduos dali "tão particularmente acostumados ao convívio com outras culturas, que a sua internacionalização não deixa de ser um imperativo natural. (SUAREZ, 2013, p. 2). 


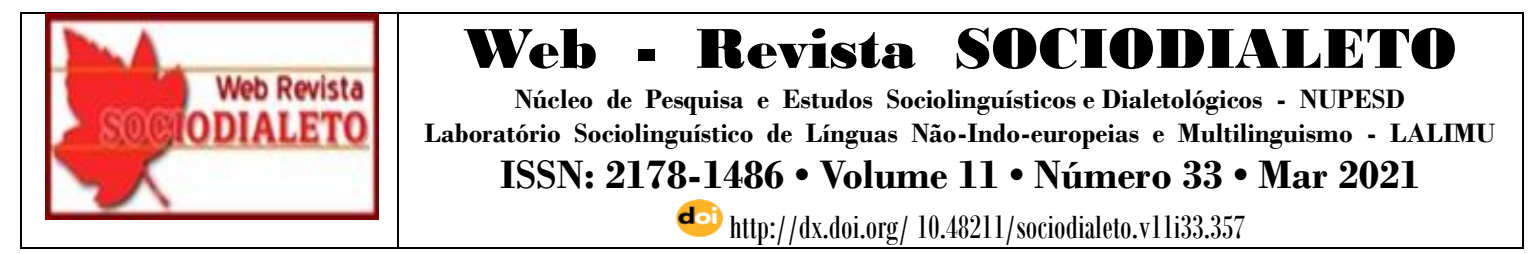

A partir desta discussão, somos direcionados ao entendimento de que as cidades que vivem a dinâmica de fronteira são receptíveis às transformações. É em virtude disso que a variação no espaço de fronteira tem sido um tema amplamente estudado nos últimos anos, pois os fenômenos que surgem a partir do contato com diferentes línguas é o motivo pelo qual muitas pesquisas têm-se voltado para o fenômeno da variação linguística.

Partindo do princípio básico de que todas as línguas estão passivas à modificação, Guisan (2009, p. 19) declara que o "sistema [linguístico] é dinâmico por essência, consistindo num organismo vivo". É nesta mesma direção que Mollica (2004, p.12) ressalta que "todo sistema linguístico se encontra permanentemente sujeito à pressão de duas forças que atuam no sentido da variedade e da unidade". A teoria da variação rompe de vez com o "mito da homogeneidade linguística" proposto pela corrente estruturalista de Saussure e gerativista de Chomsky. Coelho (2012) e Reis (2011) abrem espaço para o entendimento de que as mudanças fazem parte da natureza das línguas e, quando expostas ao convívio com outras línguas, essas transformações são perceptíveis e passíveis de análise.

\section{As práticas sociais e discursivas da fronteira}

Ao discutir sobre os fatores que condicionam a variação linguística, apresentaremos agora as relações e redes que interseccionam o cerne da comunidade fronteiriça, que em conjunto podem estar operando como ferramentas de mudança, constituindo, portanto, num conjunto complexo de correlações sociais que implementam a variação linguística (MOLLICA, 2015).

\subsection{Os casamentos interétnicos}




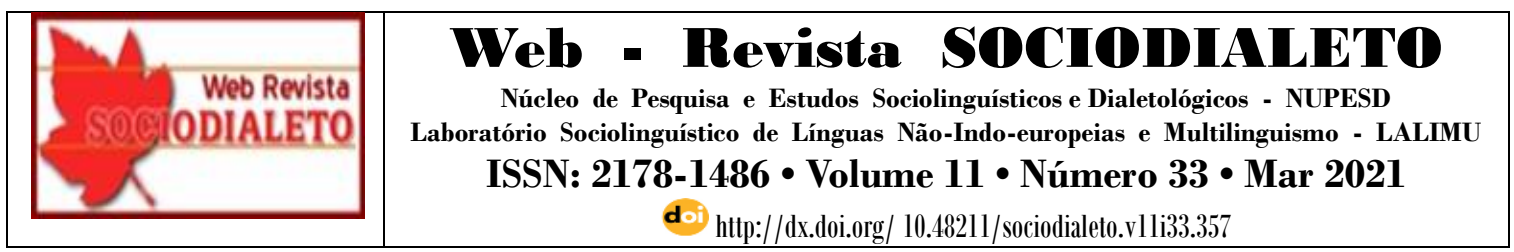

Como é de costume em realidades de fronteira, os casamentos constituídos por pessoas de nacionalidades diferentes são perfeitamente comuns. Essa prática também é observada na cidade de Tabatinga, uma vez que casamentos entre brasileiros, colombianos e peruanos compõem um sistema familiar multiétnico e racial. A respeito disso, Campos (2009, p. 305) nos diz:

Devido a essa necessidade de sobrevivência, as famílias foram se misturando por meio de uniões oficiais e não oficiais e apresentam integrantes das duas nacionalidades. As autoridades afirmam não saber exatamente quantos estrangeiros existem em cada cidade, pois muitos possuem dupla nacionalidade e declaram uma das duas dependendo da situação (na escola, em hospitais, por exemplo). Tal nível de miscigenação deveria fazer com que pensássemos que há uma integração perfeita na região, ou seja, que na família, no trabalho ou nas ruas as diferenças nacionais foram apagadas. Entretanto, isto não ocorre, aumentando o interesse pelo estudo dessa região paradoxal.

Desse modo, ao lançarmos nosso olhar para o cenário sociofamiliar do município de Tabatinga-AM, somos conduzidos ao entendimento de que os aspectos linguísticos sofrem novos rearranjos, isto é, a partir deste novo ordenamento social que se abre espaço para a mistura de línguas. De acordo com Calvet (2002, p. 34):

Quando um indivíduo se confronta com duas línguas que utiliza vez ou outra, pode ocorrer que elas se misturem em seu discurso e que ele produza enunciados "bilíngues". Aqui não se trata mais de interferência, mas podemos dizer de colagem, de passagem em um ponto do discurso de uma língua a outra, chamada de mistura de línguas.

De acordo com estas implicações, a utilização de línguas diferentes no domínio familiar passa a fazer parte da interação. Entretanto, Silva (2011) esclarece que se a família adotar uma política monolíngue, então todos assim serão; contudo, se optar pela política de adição, logo as gerações sucessivas se tornarão bilíngues, dotando os envolvidos de competência linguística em ambas as línguas, criando pressões para a utilização dos dois códigos dentro do contexto familiar. 


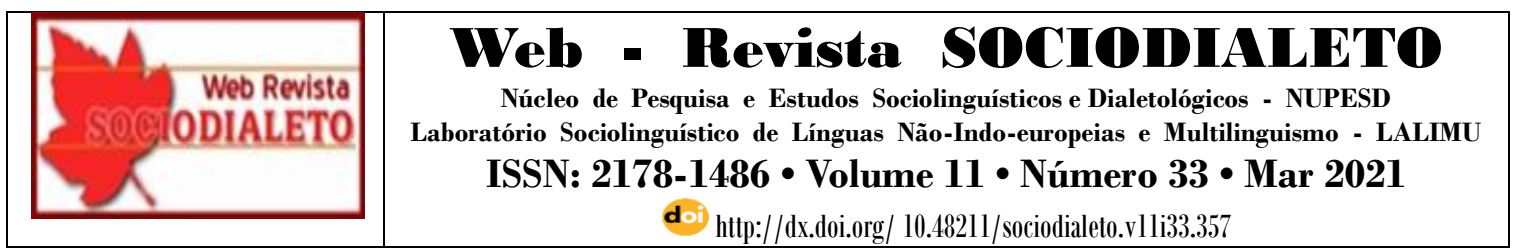

Para esse mesmo autor, "o uso da língua no lar e a transmissão para as gerações sucessoras são fundamentais para o destino de uma língua" (SILVA, 2011, p.134). Isso deixa claro que a formação familiar de que muitos tabatinguenses são oriundos pode estar atuando como ferramenta de inovação linguística, em contato efetivo com a língua espanhola.

\subsection{Políticas educacionais}

Visando contemplar a realidade linguística vivenciada por determinadas populações, foi promulgada a lei 11.161/2005 que tornou obrigatório o ensino da língua espanhola nas escolas brasileiras que fazem limite com países hispânicos. Por se enquadrar nesse requisito, desde o ano 2005, as escolas de Tabatinga disponibilizam o ensino da língua espanhola no seu currículo.

Pelo alto índice de alunos brasileiros em escolas colombianas e de alunos colombianos em escolas brasileiras, é possível afirmar que ambas as fronteiras têm grande abertura para alunos estrangeiros.

$\mathrm{O}$ ingresso de alunos no lado oposto da fronteira faz com que haja interações em redes comunicativas diversas entre brasileiros, colombianos e peruanos, isto é, em português e em espanhol. A respeito da política adotada em regiões de fronteira, Espiga (2006, p. 261) recorda que:

Do ponto de vista político e educativo, conhecer o relacionamento que ocorre entre português e o espanhol nessas zonas de contato, torna-se condicionante, diante das políticas de integração entre os países, no sentido de reconhecer e respeitar as peculiaridades culturais e linguísticas regionais, especialmente em fronteiras, e, ainda, subsidiar ações pedagógicas a tais especificidades.

Segundo Mello (2011, p.148), nesses cenários linguísticos, “a escola pode funcionar como catalizador" da manutenção de dois códigos linguísticos dentro da 


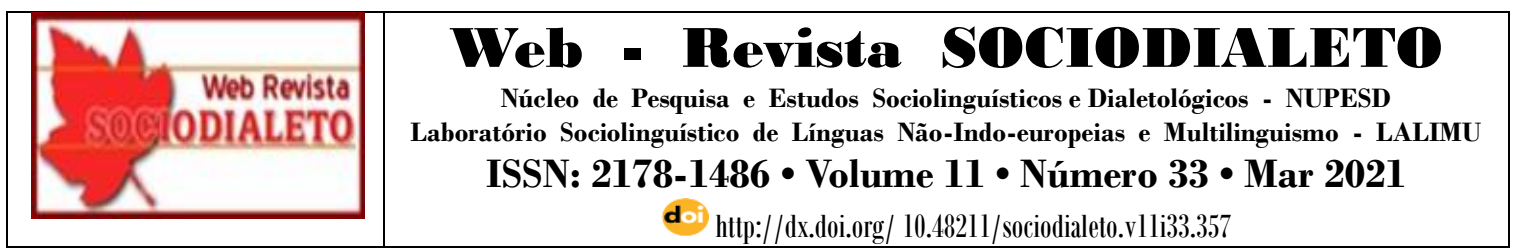

sociedade. De igual modo, Mickey (1972 apud Mello 2011), considera a escola como domínio linguístico privilegiado para manifestação do fenômeno bilíngue.

\subsection{Exposição midiática - TV}

De acordo com Moraes (2005, p. 301), de todos os meios de comunicação a tv é um dos que mais exerce influência nas pessoas, isto porque a televisão está presente em quase todos os lares, o que a torna uma ferramenta bastante difundida no meio social.

Com isso, as informações veiculadas pelo aparelho de televisão "não se encerram quando a programação acaba", pois as informações por ela projetadas repercutem nos demais segmentos sociais: em casa, no trabalho, na escola, no clube "ou em qualquer outro espaço de interação verbal" que, de maneira geral, podem também contribuir para as inovações linguísticas.

A mídia televisiva em Tabatinga é notavelmente peculiar, pois se apresenta em formato bidialetal graças à proximidade fronteiriça com a cidade de Letícia. Este fato possibilita aos moradores de Tabatinga sintonizar os canais de emissoras colombianas como, Canal Uno, Canal Caracol, Canal La Señal, fazendo com que muitos falantes de Tabatinga acessem livremente a programação brasileira e colombiana.

As novelas e seriados como Maria do Bairro (Maria del Bairo), A Usurpadora (La Usurpadora), Coração Indomável (Corazón Indomable), Chaves (El Chavo) nas demais regiões brasileiras estão disponíveis somente em português. Já em Tabatinga, os moradores têm acesso a essas programações na língua espanhola (íntegra) e no formato português (traduzida).

Dessa forma, ao ultrapassar as fronteiras físicas, a exposição midiática pode ser uma fonte de deslocamento da língua espanhola para os demais domínios linguísticos de Tabatinga, tornando a cidade uma zona que contribui para o convívio do português e espanhol. 


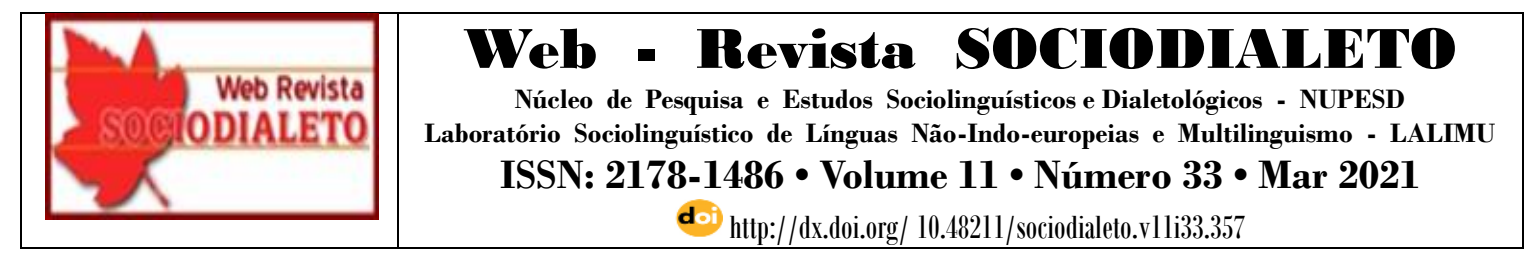

\subsection{Atividades laborais}

Um outro aspecto social que pode estar configurando o falar tabatinguense é a presença de muitos colombianos e peruanos que trabalham na fronteira brasileira, de igual modo, muitos brasileiros exercem suas profissões na cidade colombiana.

É comum que esses ambientes conduzam o falante a duas possibilidades: i) dentro da dinâmica do trabalho as duas línguas sejam utilizadas, e convivam harmoniosamente; ou ii) os dois códigos linguísticos convivam compartimentados, de modo que se adote uma única língua no exercício da profissão. Nesse segundo caso, os falantes de ambos os lados da fronteira são "obrigados" a falar a língua do ambiente do trabalho, podendo leválos a absorver os traços da língua de profissão. Nos dois casos acima citados, faz da língua uma ferramenta de "trocas simbólicas". No primeiro caso, os colombianos e peruanos que trabalham em Tabatinga passam a utilizar livremente o espanhol. Nessa situação, os demais trabalhadores ou empregadores brasileiros convivem cotidianamente com a língua espanhola. Muitas pesquisas têm demonstrado que esses contextos podem ser considerados como zonas de transição.

Já no segundo caso, ao privilegiar uma única língua no ambiente de trabalho, brasileiros que trabalham em Letícia (Colômbia) e Santa Rosa (Peru) são "levados" a adquirir o espanhol. Portanto, tanto o contexto (i) como o contexto (ii) atuam como meio de influência linguística que, em síntese, contribuem para a variação linguística em Tabatinga.

\subsection{Manifestações culturais}




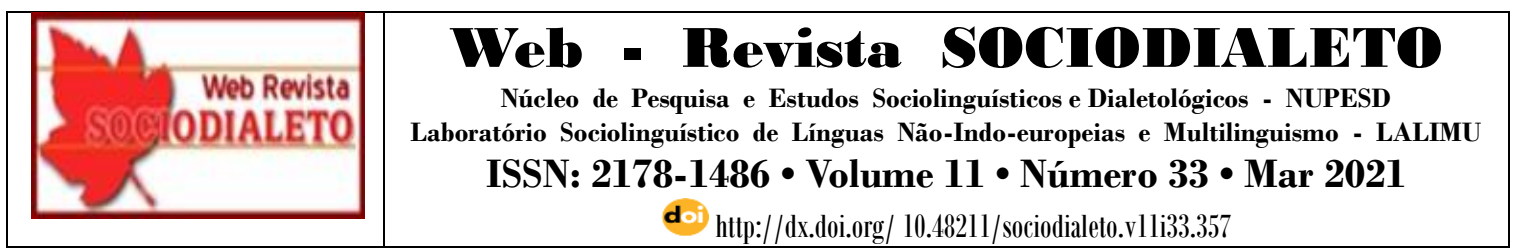

As festividades são espaços e eventos de manifestação cultural das crenças e costumes dos que ali vivem. Dentro de qualquer cultura, as tradições festivas marcam concretamente a realidade íntima e particular de cada povo.

Assim como qualquer outra cidade, Tabatinga possui várias festividades. Dentre elas, a tradicional festa religiosa de Santos Anjos, que é organizada todos os anos pela igreja católica. Outra grande festividade é o Festisol, que enaltece a cultura indígena. Nessa festa são dedicados quatro dias a competição folclórica das tribos Omáguas e Tikuna, representadas, respectivamente, pela Onça preta e Onça pintada.

Mas, por ser naturalmente pluriétnica, algumas festividades são realizadas dentro da cidade de Letícia-Colômbia. Todos os anos é realizado o Festival de la Confraternidad Amazónica, também chamada de Festa da união dos povos, que busca a integração cultural, esportiva, econômica entre as cidades que compõem a tríplice fronteira Brasil, Colômbia e Peru.

A festa tem duração de cinco dias, e nos últimos três dias a organização das apresentações fica a cargo de cada país. Nesse evento, Brasil, Colômbia e Peru selecionam una senhorita a fim de representar a beleza da mulher brasileira, colombiana e peruana, demonstrando o que há de mais marcante e peculiar em cada povo.

Outra tradicional festa é El Festival Pirarucu de Oro, que é realizado todos os anos na Concha Acústica do parque Orellana. A abertura fica por conta do Grupo sinfônico da Universidade Central da Colômbia, onde é entoado o hino nacional de cada país, reafirmando "la irmandad" e a integração dos países que compõem a tríade fronteiriça.

Nesta festa, as culturas se entrecruzam através das músicas (festival de composição e interpretação), danças, ritmos e a tradicional feira gastronômica, onde é possível degustar dos sabores característicos dos três países.

Analisando o cenário de contato, alinhamo-nos à constatação de Gorovitz (2012, p.79), que afirma: 


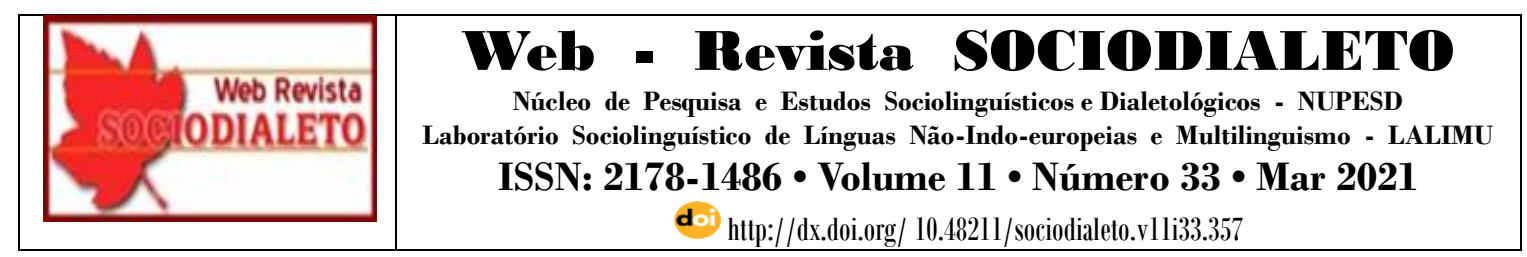

Chega-se paulatinamente à constatação de que as comunidades linguísticas em que as dinâmicas de língua se atualizam, além de gerarem formas inusitadas de mudança e de evolução, não são absolutamente homogêneas. São espaços sociolinguísticos de contatos em que, seja qual for a natureza da interação e da situação discursiva, a produção se inscreve em uma organização discursiva que a marca, a sanciona e a determina. Não há língua sem discurso e não há discurso sem referência histórica e social, sem constrangimentos e sem normas; ou seja, toda produção é especializada, coagida e condicionada pela sanção coletiva, que não tem objetividade.

\section{Considerações Finais}

A realidade sociocultural de Tabatinga, como vimos, contempla um acentuado dinamismo de relações além de suas fronteiras, transformando o norte brasileiro em uma sociedade singular e pluriétnica "y allí se han mezclado las economías, los pueblos y las culturas, para formar una sociedad trinacional y multiétnica totalmente nueva" (GOBERNACIÓN DEL AMAZONAS, 1999, p.53).

Em rápida análise contextual, é razoável afirmar que a sociedade tabatinguense está imergida em múltiplas culturas que não lhes são próprias, mas que pelo convívio cotidiano, tais culturas se entrecruzam de modo natural. Em razão disso, Suarez (2013, p. 2) esclarece que

os vínculos familiares que se conformam em ambos os lados da fronteira, entornos próximos e parecidos, práticas religiosas, lendas e crenças similares, gostos alimentícios compartidos, produto da constante e cotidiana mobilidade e o intercâmbio econômico e cultural, propiciam vínculos interativos que os fazem formar parte de uma história compartida.

Para Borstel (2006, p. 283), "é o modo de viver e de falar de uma determinada comunidade, manifestando-se na língua, na arte, no sistema social, nos hábitos, costumes, religião e festas" o que comprova que as práticas e os discursos oriundos do contato com outros povos são determinantes para a variação dentro deste espaço fronteiriço difuso e diversificado. 


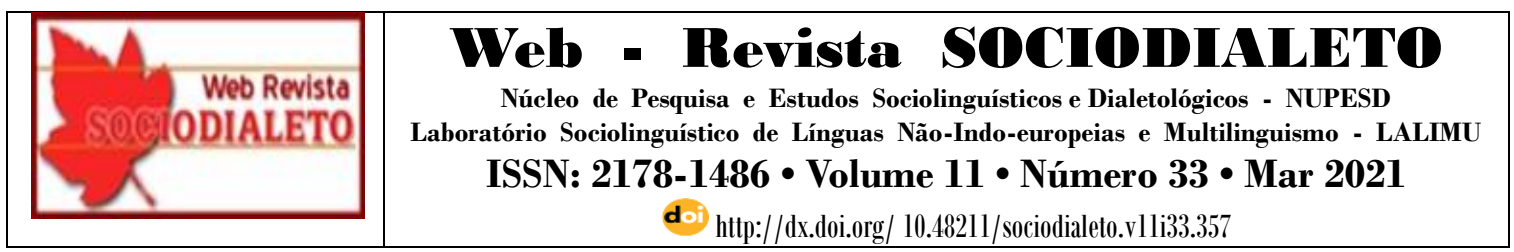

Como foi possível observar, nosso objetivo neste trabalho não visou à análise de dados da variação existente dentro do espaço de fronteira. Trataremos destes dados em futuras pesquisas, quando analisaremos com minúcia cada item variável observado na fala tabatinguense. Nossa intenção aqui foi descrever e analisar como e quais práticas sociais e discursivas implementam a variação que realçam esta região cosmopolita e pluriétnica.

\section{Referências}

ALKMIM, Tânia. Sociolinguística- parte I. In MUSSALIM, Fernanda; Bentes, Ana Christina (Orgs.). Introdução a linguística: Domínios e fronteira. v. 1.- São Paulo: Cortez, 2012, p. 23-50.

BENVENISTE, E. Problemas de linguística Geral. São Paulo: Editora NacionalEDUSP, 1976.

BRANDÃO, Silvia Figueiredo. A história e as contribuições de um projeto na linga Geolinguística. In: Vanderci de Andrade Aguilera. (Orgs). A geolingüística no Brasil: Trilhas a seguir, caminhos a percorrer.- Londrina : Eduel, 2013, p. 357-370.

CALVET, Louis-Jean. Sociolinguística: uma introdução crítica/ Louis-Jean Calvet; tradução Marcos Marciolino - São Paulo: Parábola, 2002

CAMPOS BARBOSA, Gabriela de. Atitudes em fronteira: O caso de Tabatinga e Letícia. Forma y Función, 2008, (21), 303-324. ISSN: 0120338X. Disponível em: https: //www.redalyc.org/articulo.oa?id=21911525013.

CHAGAS, Paulo. A mudança linguística. In. FIORIN, Luiz, José. (Org.). Introdução à linguística I - Objetos teóricos.- 6 . ed. 4 impressão.- São Paulo, 2015.

COAN, Marluce. Tempos Variáveis: Os mais que perfeitos simples e composto e perfeito simples em variação e mudança do século XVI ao século XX. In: VANDRESEN, Paulino. (Org.). Variação, mudança e contato linguístico no Português da região Sul. - Pelotas: Ed: EDUCAT, 2006. p. 77-98.

COELHO, I. L. et al. Sociolinguística. Florianópolis: LLV/CCE/UFSC, 2012.

DIAS, Juçá Fialho Vazzata. A concordância de Número nos Predicativos e nos Particípios Passivos na fala região Sul: um estudo variacionista. Florianópolis. Dissertação de Mestrado, 1996.

ESPIGA, Jorge. O contato do Português com o espanhol da região sul do Brasil. In. VANDRESEN, Paulino. (Org.). Variação, mudança e contato linguístico no Português da região Sul. - Pelotas: Ed: EDUCAT, 2006. p. 261- 279. 


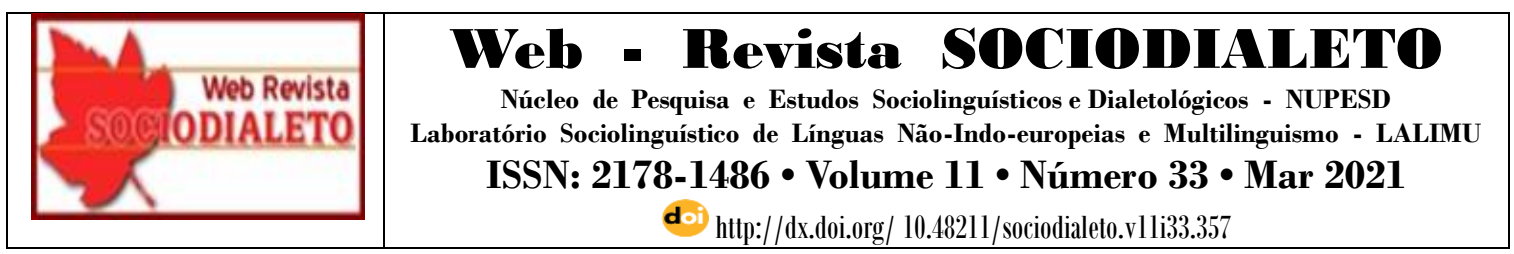

GARCIA, F. Cacciatore de. Fronteira iluminada. História do Povoamento, conquista e limites do Rio Grande do sul a partir do Tratado de Tordesilhas (1420-1920). Porto Alegre: Sulina, 2010.

GOROVITZ, S. A tradução como contato de línguas, Brasília, 2012: Universidade de Brasília. Disponível

em periodicos.unb.br/index.php/traduzires/article/download/8052/6122, acesso em $12 / 08 / 2017$.

GUISAN, Pierre. Língua: A ambiguidade do conceito. In. BARRETO, M. M.G.S \& (Org). Sociolinguística no Brasil: Uma contribuição dos estudos sobre línguas em contato.- Rio de Janeiro : 7letras, 2009. P. 17-29.

LABOV, W. Sociolinguistic patterns. Philadelphia: University of Pennsylvania, 1972.

MELLO, Heloísa Augusta Brito de. Atitudes linguísticas em uma comunidade Bilíngue do sudoeste goiano. In. SILVA, Sidney de Souza. (Org). Línguas em Contato: Cenários de bilinguismo no Brasil.- Campinas: Ed: Pontes, 2011. P. 141-177.

MOLLICA, Maria Cecília; BRAGA, Maria Luíza. (Orgs). Introdução à Sociolinguística: o tratamento da variação. $2^{\mathrm{a}}$ ed. São Paulo: Contexto, 2004.

MOLLICA, Maria Cecília. Fundamentação teórica: Conceito e delimitação. In. MOLLICA, M. C; BRAGA, M. L. Introdução a sociolinguística: o tratamento da variação.- 4, ed., 3 reimpressão. São Paulo : Contexto, 2015.

OGLIARI, Marlene Maria. Línguas Minoritárias e situações bilíngues decorrentes: considerações sociolinguísticas. In. VANDRESEN, Paulino. (Org.). Variação, mudança e contato linguístico no Português da região Sul. - Pelotas: Ed: EDUCAT, 2006.

PADOVANI, Bruna F. S. Lima de. SANCHES, Romário, D. Interface da sociolinguística e a dialetologia. Web-Revista Sociodialeto, V.6. n: 18, 542-567, 2016. Disponível em: www.sociodialeto.com.br/edicoes/24/28092016110318, Acesso em 13/09/2020.

PEIXOTO, Paulo de Tarso. C. de. Multiculturalismo, transculturalismo, e heterogênese urbana: Composições da diversidade para a produção do transconhecimento. Revista Científica da Faculdade Salesiana Maria Auxiliadora, n: 7, p. 2, 2009. Disponível em www.fsma.edu.br/visoes/ed08/Edicao_8_artigo3.pdf, Acesso em 01/09/2020.

REIS, P. C. et al. A sociolinguística e o ensino de língua materna, X Congresso Nacional de Educação-Educere, Paraná, 2011

SUAREZ. Á. G. "Tabatinga (Br) e Letícia Col): Duas cidades Gêmeas. Disponível em http://www.aebr.eu/files/publications/, Acesso em 09/11/2020.

Recebido em: 31/10/2020 | Aprovado em: 18/01/2021. 